\title{
NIST Technical Note 2008
}

\section{Alerting under Imminent Threat: Guidance on alerts issued by outdoor siren and short message alerting systems}

\author{
Erica D. Kuligowski \\ Amanda Kimball
}


NIST Technical Note 2008

\section{Alerting under Imminent Threat: Guidance on alerts issued by outdoor siren and short message alerting systems}

Erica D. Kuligowski

Fire Research Division

Engineering Laboratory

Amanda Kimball

Fire Protection Research Foundation

This publication is available free of charge from:

https://doi.org/10.6028/NIST.TN.2008

August 2018

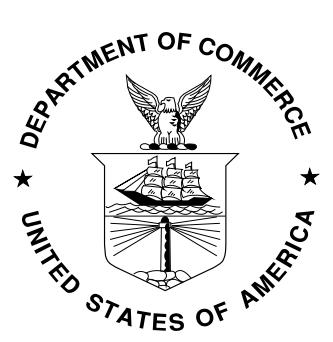

U.S. Department of Commerce Wilbur L. Ross, Jr., Secretary

National Institute of Standards and Technology Walter Copan, NIST Director and Undersecretary of Commerce for Standards and Technology 
Certain commercial entities, equipment, or materials may be identified in this document in order to describe an experimental procedure or concept adequately. Such identification is not intended to imply recommendation or endorsement by the National Institute of Standards and Technology, nor is it intended to imply that the entities, materials, or equipment are necessarily the best available for the purpose.

National Institute of Standards and Technology Technical Note 2008

Natl. Inst. Stand. Technol. Tech. Note 2008, 27 pages (August 2018) CODEN: NTNOEF

This publication is available free of charge from:

https://doi.org/10.6028/NIST.TN.2008 


\section{Acknowledgements}

The authors would like to thank the Fire Protection Research Foundation (FPRF) for sponsorship of the Project Technical Panel. The members of the Technical Panel are listed here:

- Daniel Gorham, Fire Protection Research Foundation

- Jodie Andrew, American Red Cross

- $\quad$ Pete Brewster, U.S. Department of Veterans Affairs

- Bill Bunting, National Oceanic and Atmospheric Administration (NOAA)/National Weather Service (NWS) Storm Prediction Center

- Otto Drozd, Orange County Fire Rescue Department

- Gina Eosco, Cherokee Nation Strategic Programs

- Denis Gusty, U.S. Department of Homeland Security

- Dean Larson, Larson Performance Consulting

- Edward Lent, International Association of Emergency Managers

- Joy Lueck, American Signal Corp.

- Bethany Perry, National Oceanic and Atmospheric Administration (NOAA) Central Region Collaboration Team

- Keith Stammer, Joplin/Jasper County Emergency Management Agency

- Jeannette Sutton, Ph.D., University of Kentucky

- Michele Wood, Ph.D., California State Fullerton

- Brian O’Connor, National Fire Protection Association (NFPA) Staff Liaison

Input and insight from the Technical Panel was integral in the development of this document. Also, thank you to Richard Peacock and Nelson Bryner from NIST, and Daniel Gorham from the Fire Protection Research Foundation for a comprehensive review of the document before publication.

Thank you to the Principal Sponsors: IMSA, The Association of Electrical Equipment and Medical Imaging Manufacturers (NEMA) 3SB, and Tyco, as well as to the Participating Sponsors: Automatic Fire Alarm Association (AFAA) and Honeywell. 


\section{Abstract}

The National Institute of Standards and Technology (NIST)'s Technical Investigation of the 2011 Joplin, MO tornado identified that no widely accepted standards exist for emergency communications in tornado events and more specifically, policies involving the use of communication systems to alert the public in advance of tornadoes. This publication provides evidence-based guidance for communities on the creation and provision of public alerts, including both alerts provided by outdoor siren (warning) systems and "short messages" sent by social media or other short message service (SMS) platforms. It is the hope that this guidance can eventually be used as input for standardization, through codes and standards, of the procedures and practices for outdoor siren systems and short message alerts used by communities across the United States. Standardization of emergency communication policies and procedures could occur at multiple levels, including among multiple jurisdictions, state-wide, regionally, or even nationally.

This document begins with a brief background on alerting systems, focusing specifically on outdoor siren systems and short message alerts. The next section presents the methods used for the development of evidence-based guidance on public alerts, including methods for review of literature on public response to public alerting systems, the development of preliminary guidance based on these reviews, and the finalization of the guidance presented here in this report. Then, guidance for communities on the creation and provision of public alerts for those under imminent threat is presented. This document ends with a discussion on unanswered questions, providing opportunities for further research into various areas of public alerting.

Keywords: alerts, disasters, emergency communication, mass communication, short messages, Twitter, Wireless Emergency Alerts, IPAWS, public response, emergency warnings, tornadoes, outdoor siren systems 


\section{Table of Contents}

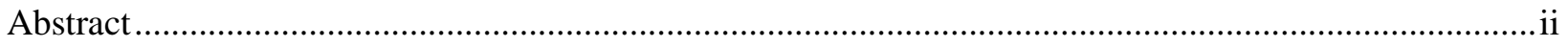

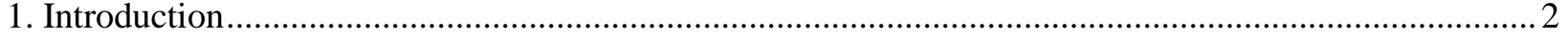

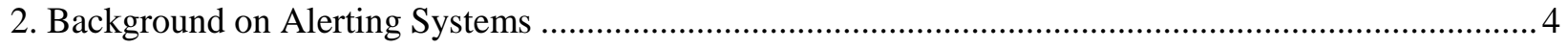

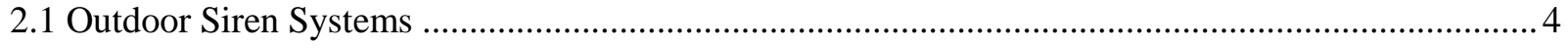

2.2 Short Message Alerts ................................................................................................................. 5

3. Methods for Guidance Development ……....................................................................................... 7

31. Literature Review on Public Response to Auditory Alerts............................................................ 7

3.2 Literature Review on Public Response to Short Message Alerts..................................................... 8

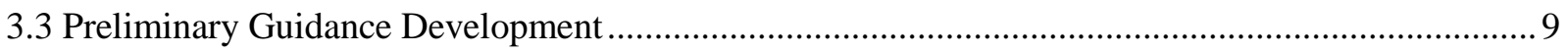

3.4 Workshop Development and Outcomes .................................................................................... 10

4. Guidance on Public Alerting under Imminent Threat......................................................................... 10

4.1 Guidance on Outdoor Siren System Alerting for Those Under Imminent Threat ........................... 11

4.2 Guidance on Short Message Alerting for Those Under Imminent Threat ....................................... 14

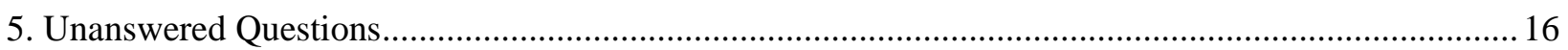

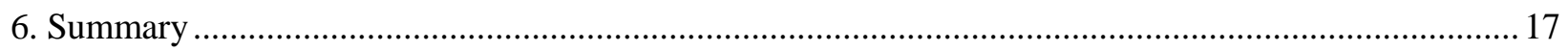

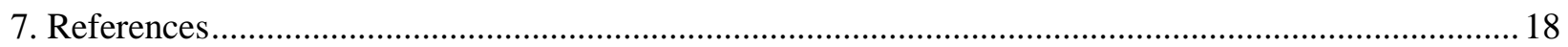




\section{Introduction}

Tornadoes pose a significant threat to life and property in the United States. In an average year, these windstorms are responsible for the most fatalities and insured losses of any natural hazard in the U.S. For example, in the ten years from 2001 to 2010, the U.S. averaged nearly \$1B in insured losses and 56 fatalities per year from tornadoes according to the National Oceanic and Atmospheric Administration (NOAA 2014). One of the deadliest U.S. tornadoes on record was one that struck the city of Joplin, MO and surrounding areas on May 22, 2011.

The tornado that occurred on May 22, 2011 in a populated area, Joplin, Missouri was rated as a National Weather Service (NWS) EF-5 tornado on the Enhanced Fujita tornado intensity scale (NOAA 2011). This tornado touched down just to the west of Joplin and proceeded to cut a swath across the entire city. The tornado directly affected 41 percent of the city's population (20 820 people, out of the 50175 estimated), damaged or destroyed nearly 8000 structures and caused nearly \$2B in insured commercial and residential property losses, and generated approximately $2.29 \times 10^{6} \mathrm{~m}^{3}\left(3 \mathrm{M} \mathrm{yd} \mathrm{d}^{3}\right)$ of debris (Kuligowski et al. 2014). More importantly, the structural damage and associated windborne debris were responsible for the majority of the 161 fatalities, the most caused by a single tornado since the NWS started keeping records in 1950. Windborne debris was also a major factor in the over 1000 injuries reported from the tornado, which also included a large number of debris impacts.

Given the unprecedented number of fatalities and injuries, as well as the scope and extent of structural damages caused by the May 22, 2011 Joplin, MO tornado, the National Institute of Standards and Technology (NIST) formally established a team to investigate the disaster under the National Construction Safety Team (NCST) Act (Public Law 107-231). The team consisted of the four NIST researchers - with expertise in structural and fire engineering, wind science and engineering, and sociology - and a researcher from the National Oceanic and Atmospheric Administration's National Severe Storms Laboratory (NOAA's NSSL) with expertise in meteorology, severe storms and warnings.

The NIST Investigation's goals were to: (1) study the wind environment and conditions associated with fatalities and injuries, the performance of emergency communications systems and public response to such communications, and the performance of residential, commercial, and critical (e.g., hospital) buildings, designated safe areas in buildings, and lifelines; and (2) develop findings and recommendations that serve as the basis for potential improvements to public safety in tornadoes, including:

- Potential improvements to requirements for design and construction of buildings, designated safe areas, and lifeline facilities in tornado-prone regions;

- Potential improvements to guidance for tornado warning systems and emergency response procedures; and

- Potential revisions to building, fire, and emergency communications codes, standards, and practices.

Several findings from this investigation focus specifically on emergency communications (Kuligowski et al. 2014). First, there were the multiple ways in which individuals in Joplin, MO were made aware and received further information about the May 22, 2011 tornado emergency. Joplin’s outdoor siren system, which could generally be heard indoors as well as outside, was the primary means by which individuals 
were alerted to a tornado event. Radio, television, and word of mouth were the primary means by which individuals were provided with warning information. Second, functioning as an alerting system only, the outdoor sirens prompted many Joplin residents and visitors to seek further information. However, the multiplicity of information sources, and the conflicting information provided by those sources, added to the public's confusion about the true hazard as additional information was sought. In turn, responses to the approaching tornado among members of the public, in many cases, were delayed or incomplete, as was evidenced by the fatalities that occurred among individuals located outdoors, in vehicles, or en route within buildings to safer refuges when the tornado hit. The two main factors that contributed to delays in or incomplete response to the Joplin, MO tornado were: 1) a lack of awareness of the tornado, and 2) an inability to perceive personal risk due to a) receiving conflicting or uncertain information about the tornado, b) holding pre-existing beliefs about Joplin's immunity to direct tornado strikes, or 3) distrust or confusion about Joplin's emergency communications system.

Another significant finding was that no widely accepted standards exist for emergency communications in tornado events. In response to these findings from the investigation, NIST recommended "the development of national codes and standards and uniform guidance for clear, consistent, recognizable, and accurate emergency communications, encompassing alerts and warnings, to enable safe, effective and timely responses” (Kuligowski et al. 2014).

With the extensive use of outdoor siren systems in tornado prone areas and the rising use of social media and other platforms that can provide information via mobile devices, this study focused on developing evidence-based guidance for communities on the creation and provision of public alerts. Here, public alerts include both alerts provided by outdoor siren (warning) systems and "short message alerts" (i.e., messages with a specific character restriction sent by social media or other short message service [SMS] platforms). It is the hope that this guidance can eventually be used as a basis for standardization, through codes and standards, of the procedures and policies for public alerting used by communities across the United States. Standardization of emergency communication policies and procedures could occur at multiple levels, including among multiple local jurisdictions, state-wide, regionally, or even nationally.

In 2017, a NIST Technical Note was published on outdoor siren systems (Kuligowski and Wakeman 2017). This Technical Note provided an overview on the current status of siren systems in the United States, as well as a review of the literature on the ways in which people respond to alerting signals (including siren systems) and the current limitations of outdoor siren systems in light of these findings. In 2018, a NIST Technical Note was published on short message alerts (Kuligowski and Doermann 2018). Short message alerts are messages with specific character restrictions - e.g., 90 or 280 characters in length - that are meant to alert individuals (under imminent threat) that something is wrong and that more information is available (elsewhere) on the emergency. This Technical Note provided an overview on the current status of short message alerting in the United States, focusing Wireless Emergency Alerts (WEAs) disseminated via the Integrated Public Alert \& Warning System (IPAWS), and alerts disseminated via Twitter. Additionally, this report presented a review of the literature on the ways in which people respond to short message alerts during emergencies and the current limitations of these types of alerts in light of these findings. Both Technical Notes (on outdoor siren systems and short message alerts) discuss the key findings and recommendations from the literature on the possible ways in which to improve alerts for people under imminent threat, based on the methods by which people receive and process alerts.

This current document presents the overall evidence-based guidance for communities on the creation and provision of public alerts. This focus of this guidance is on the creation and provision of alerts using 
outdoor siren systems and short message alerting platforms. First, this document presents a brief background on alerting systems, focusing specifically on outdoor siren systems and short message alerts. The next section presents the methods used for development of evidence-based guidance for communities on the creation and provision of public alerts. This methods section includes a discussion of the methods used to review literature on public response to public alerting systems (see Kuligowski and Wakeman [2017] for a review of public response to audible alerting systems and Kuligowski and Doermann [2018] for a review of public response to short message alerts), the methods used for development of preliminary guidance based on these reviews, and the methods used to finalize the guidance presented here in this report. Next, guidance is presented on both outdoor siren system alerting and short message alerts targeting members of the public under imminent threat. This document ends with a discussion on unanswered questions, providing opportunities for improving understanding in various areas of public alerting.

\section{Background on Alerting Systems}

In the event of community-wide emergencies, such as tornadoes, tsunami, wildfires, or hazardous chemical spills, alerts and warnings are issued with the goal of initiating protective action among the public. Sheltering in place or evacuating to safety are two examples of protective actions. The main purpose of alerts is to capture the attention of the public in preparation for a subsequent warning message. Warnings are then used to provide information about the emergency, such as emergency type, when it will manifest, and the forms of protective action that should be taken (Kuligowski et al. 2014).

Although a variety of different alerting systems exist, this project and subsequent guidance has focused on alerts provided by outdoor siren and short message systems. A brief overview is provided on each of these systems here; and further information can be found in the associated literature reviews on each system (e.g., Kuligowski and Wakeman [2017]; Kuligowski and Doermann [2018]).

\subsection{Outdoor Siren Systems}

Depending upon emergency type, alerts are often disseminated using outdoor siren systems. These systems are meant to alert individuals located outside of structures within the community of an impending emergency; however, people often hear them indoors and many even rely upon these systems as a means of alerting them inside of structures (Stokoe 2016; Kuligowski et al. 2014).

Overall, there are many different types of siren technology, as well as various ways in which these technologies are employed to alert community members of an impending disaster. Based upon a review of 53 systems from four manufacturers, outdoor siren systems can differ by the following categories:

- The type of system (i.e., electro-mechanical vs. electrical systems differ in the method by which sound is provided),

- Voice communication capabilities,

- $\quad$ Signal capabilities (e.g., the number of tones disseminated by the system),

- The direction of the sound (i.e., the coverage area of the siren system and its method of achieving that coverage [e.g., rotating or stationary]),

- The continuity of sound (i.e., the time period allowed for continuous operation, before a cooling down period must begin), and

- The testing options available to verify that the siren is still functioning appropriately. 
With many communities using siren systems to alert the public, compounded by the various types and capabilities of siren technology and the lack of standardization among U.S. community siren usage procedures (Kuligowski et al. 2014; Laidlaw 2001), it is no surprise that the usage of siren systems differs widely from community to community across the U.S. More specifically, siren system usage differs in the following ways: the types of tones used for alerting, the meaning of these tones (i.e., what one should do when the alert is sounded), and activation protocols (i.e., when or in what types of conditions the alert should be activated). Testing protocols and the use of all-clear signals (i.e., additional alerts signaling the end of an emergency) also vary by jurisdiction (Brotzge and Donner 2015; Kuligowski et al. 2014).

First, the signal or tone of a siren system is a key way in which sirens differ across U.S. communities. Both multi-tonal (i.e., the siren system can disseminate more than one type of tone) and single-tonal systems are common in the U.S. Additionally, alerting tones, even for the same type of emergency, often differ depending on geographic location (Kuligowski et al. 2014).

Next, the siren tones do not inherently convey much information; however, meaning can be assigned to an outdoor siren system tone, which can then be taught to the public. This "meaning" can and does vary across U.S. communities as well. Tone meaning usually falls into one of two categories; a general "seek out information” meaning, or a more specific meaning that is linked to a particular hazard type.

Siren usage also differs with regards to activation procedures. Activation procedures can range from more to less inclusive. More inclusive activation procedures can include activating the siren system for various types of hazards and levels of hazard severity. e.g., severe thunderstorms, tornado watches, and tornado warnings disseminated by the National Weather Service that occur both within and nearby the community in question. Less inclusive activation procedures can include activating the siren only for tornado warnings issued for areas within the community. In turn, the siren may sound more frequently in one community over another from year to year.

Finally, outdoor siren usage can differ by testing protocols and the use of all-clear signals. The frequency of testing, as well as the test's duration, schedule, and tone can vary by community. Additionally, although most jurisdictions no longer used all-clear signals to alert the public that the emergency had ended; this finding was not consistent across all sampled communities (Brotzge and Donner 2015).

While outdoor siren systems represent a key component to a community's "alerting toolbox", it is clear that diversity exists among outdoor siren system technology and its usage. Therefore, guidance on the use of these systems can benefit the public in two ways: 1) prompt more effective and safer public response and 2) help to standardize the use of these systems, and in turn, potentially decrease confusion associated with their use.

\subsection{Short Message Alerts}

Short messages, or terse messages, are limited-character alerting messages (e.g., 90 to 360 characters) provided via various platforms and channels, e.g., mobile technology. A confusion with short message alerts is whether they serve as alerts or warnings during disasters. While short message platforms contain the ability to alert the public, especially if pushed out to devices or placed on "notification mode", the current character limits are insufficient to include all necessary warning information. For that reason, they are often referred to as "alerts" rather than warning messages/systems.

Short message alerts can be disseminated for all hazards. Additionally, they may be pushed out to individuals via mobile technology based on geographic location of nearby cellular towers (i.e., Wireless 
Emergency Alerts or WEAs) or disseminated via social media or mobile applications only to those who subscribe to and/or follow specific platforms and accounts within those platforms.

Overall, there are different types of short message platforms. The focus of this study has been on short message alerts provided via IPAWS as WEAs (90-character limits) and short messages provided via Twitter (280-character limits). A brief discussion is provided on both platforms; please see Kuligowski and Doermann (2018) for a comprehensive overview.

One of the systems currently available to disseminate short message alerts is Wireless Emergency Alerts (WEAs) disseminated via IPAWS, or the Integrated Public Alerting and Warning System. WEAs is a free nationwide program that began in 2011, whereby emergency messages (restricted to 90 characters in length) are sent to individual mobile devices by "authorized government alerting authorities”. IPAWS allows alerting authorities to write their own message using open standards. The alert message is then authenticated by the IPAWS open platform for emergency networks so that it can be delivered simultaneously via IPAWS-compliant public-alerting and warning channels (e.g., television, radio, cell phone, etc.).

An individual can receive WEAs directly to his/her mobile device, without the need to download an app or subscribe to a particular service. WEA messages are sent to individuals based upon their geographical location (i.e., WEAs are broadcast from area cell towers to mobile devices in the area), their type of device (i.e., it needs to be a WEA-capable phone), and their wireless carrier (i.e., the carrier must participate in the program). This is an opt-out program, in that if individuals do not wish to receive WEAs, they can opt-out of the system via settings on their mobile devices.

On September 29, 2016, the Federal Communications Commission (FCC) adopted six new WEA guidelines aiming to "promote the wider use and effectiveness of this life saving service" (FCC News 2016, p. 1). One of these new guidelines requires carriers to increase the maximum length of WEA messages from 90 to 360 characters for 4G LTE and future networks within 30 months of adoption (Federal Communications Commission 2016).

Twitter is a free news and social media site launched in 2006 that allows users to post "tweets" (i.e., messages) of up to 280 characters. Non-users of this site have the ability to read but not post. Users in Twitter create a unique profile name (e.g., @username) and in their account, have information such as their followers, the accounts they are following and their past tweets. Twitter ${ }^{1}$ is an opt-in system meaning that a user can choose to "follow" other accounts and receive their tweets, and if they do not wish to receive tweets from an account, they simply do not follow that account. Tweets can be accessed through two portals. Users have the ability to access these messages at www.twitter.com or have the messages sent directly to their cell phones in the form of a text message. Users can customize what messages are sent to them based on specific accounts, i.e., a user might choose to have messages from NWS (i.e., @NWS) come to their phone as text messages and access all other tweets online. Users also have the ability to customize the tones and vibrations that occur when they receive messages.

There are three "conventions" used in messages/tweets that make Twitter unique from other short message platforms. The first convention is a mention, denoted by an '@' symbol, which identifies a specific user within the message. This convention can simply be used to "call on someone" or can start an interactive dialogue between multiple users. The second feature is the hashtag, represented by a '\#' symbol, e.g., \#LAfire or \#SanDiegoFire. This feature is usually placed at the end of a tweet and is used to

\footnotetext{
${ }^{1}$ Certain commercial entities, equipment, or materials may be identified in this document in order to describe an experimental procedure or concept adequately. Such identification is not intended to imply recommendation or endorsement by the National Institute of Standards and Technology, nor is it intended to imply that the entities, materials, or equipment are necessarily the best available for the purpose.
} 
signify overall topics or themes of the tweet. Users also have the ability to search for tweets based on a certain hashtag (Mills et al. 2009). The final convention is the shortened URL, such as 'bit.ly'. These shortened URLs are used in place of traditional ones to aid in keeping the character count under maximum limits. These links can stand alone (as the message, itself) or accompany a message and when clicked on, take the user to an image or another webpage.

Message providers using short message alerting systems have a limited amount of space to provide important and vital alerting (or warning) information. As mentioned above, character restrictions of both platforms (WEAs and Twitters) have already expanded or will expand in the future, allowing more space to provide this vital information. However, little guidance is available, until now, on how to use the added space to prompt more effective and safer public response among those under imminent threat.

Before guidance is provided, however, a discussion of the methods used to develop guidance on the use of these alerting systems should be presented. The following section presents the methods used to develop guidance on public alerting for those under imminent threat. Methods are presented on reviews of the literature focused on public response to alerting systems, the creation of preliminary guidance, and development of the evidence-based guidance that is presented in this report.

\section{Methods for Guidance Development}

In both Kuligowski and Wakeman (2017) and Kuligowski and Doermann (2018), literature reviews were performed to better understand how the public responds to two different alerting methods: auditory alerts and short message alerts. The methods of each literature review are described in this section.

\section{Literature Review on Public Response to Auditory Alerts}

In Kuligowski and Wakeman (2017), a literature review was carried out on how people respond to auditory alerts. To begin the review process, a general search for material was performed, and sources were included or not based on their relevance to outdoor siren systems, auditory alerts, and human response to alerts. More specifically, material was selected based on whether or not it provided background on the response of the public to current audible alerting systems, the limitations of current systems in alerting the public, and/or key findings or recommendations that would improve or advance the current methods used to alert people of impending disasters.

A total of 67 sources were collected and reviewed from a variety of databases, including Google Scholar and Web of Science. The databases were searched using the following keywords: emergency, disaster, alert, siren, outdoor siren system, auditory alerts, notification, public response, education, and vulnerable populations. All material was drawn from publicly available resources, published in English. A general framework was used to extract information on each literature source, including the source of the reference, the discipline in which the source was found, a summary of the contents, and key findings and recommendations provided by the source.

Literature was selected from a variety of different disciplines. The disciplines from which literature was collected included acoustics, child development, communication, crisis management/disasters, education, ergonomics, fire, medicine, meteorology, psychology, and public health.

The 67 sources collected and reviewed fell into a variety of source types and time periods. The majority of the sources included in this review consisted of peer reviewed journal articles and conference proceedings (52 out of 67). A limited number of publications were categorized as government reports, books, and other types of reports. Also, of the 67 sources, a majority (49 out of 67) were published from 
the year 2000 to present. Only a few cited (2) were published prior to 1979, and the rest were published between 1980 and 1999.

\subsection{Literature Review on Public Response to Short Message Alerts}

In Kuligowski and Doermann (2018), a literature review was carried out on how people respond to short message alerts in the context of emergencies. To begin the review process, a general search for research was performed, and sources were included or not based on their relevance to short messages and human response to emergency-based alerts. More specifically, material was selected based on whether or not it provided background on the response of the public to short message alerts (specifically focused on WEA and Twitter), the limitations of current systems in alerting the public during disasters, and/or key findings or recommendations that would improve or advance the current methods used to alert people of impending disasters.

A total of 47 relevant sources were collected and reviewed as part of this report. The selected material is intended to present a representative - as opposed to exhaustive - view into research and best practices. All material was drawn from publicly available resources, published in English. Sources of information were found using several databases: Engineering Village, Web of Science, Web of Science: Social Science and Google Scholar. The databases were searched using the following keywords: emergency, disaster, alert, message, notification, communication, social media, text, SMS, twitter, tweet, mobile, response, interpret, react, and understand. The disciplines from which literature was collected included communication, crisis management, emergency management, disasters, psychology, sociology, geography, meteorology, and public health.

Once articles were identified, each of the articles' abstracts were reviewed for relevance. Articles deemed relevant were collected and analyzed. The purpose of this review was to identify the findings and/or recommendations made about public response to short message alerts, with a specific focus on findings from research on WEA and Twitter alerts. As with any research on disasters and human behavior, research and publications were analyzed that used hypothetical scenarios to study public behavior related to alerts/warnings. This type of research can be problematic when attempting to identify/predict how the public is likely to behave in an actual alerting or real event (National Research Council 2013).

Additionally, the research documented in the publications collected contained varying methods from one report to the next. Therefore, as part of this review, each article underwent an extensive review of its objectives, methods, findings, and recommendations. Objectives were checked for their relevance to the overall project objective. Methods were scrutinized primarily based on sample size, demographic/ locations represented, time period of data collection, and the presentation of a survey or exercise to subjects, if one was included. From all reviews, each article's findings and recommendations were collected and then categorized based on their relevance to five topics of interest. These topics were the following: comprehension and readability, credibility, personalization of the message, providing additional information, and salience. If an article was reviewed and determined to have questionable methods, its findings and/or recommendations were included in this review only if they were confirmed by other reviewed publications.

The 47 sources collected and reviewed fell into a variety of source types and time periods. The majority of the sources included in this review consisted of peer reviewed journal articles and conference proceedings (38 out of 47). A limited number of publications were categorized as government reports, books, and other types of reports. Also, all of the articles included in this review were published in 2008 
or later. This was particularly important since short message alerting and technology is a growing field, and it was found that most articles published before 2008 were already out of date. A majority of the articles reviewed were published in between 2014 and 2017 (32 out of 47).

\subsection{Preliminary Guidance Development}

Based on both literature reviews, preliminary guidance on alerting for those under imminent threat was developed. To develop preliminary guidance, each of the findings and recommendations from both reviews was prioritized using a set of criteria. The list of the criteria is presented here:

- Is the research finding or recommendation relevant to individuals in imminent danger; i.e., relates to emergency conditions rather than normal/non-emergency conditions?

- Is the research finding or recommendation relevant to large-scale disasters that occur within a community setting?

- Is the research finding or recommendation in agreement with theory and expert opinion on human behavior in emergencies?

If the finding and/or recommendation met these criteria, it was then considered as credible for inclusion into the preliminary guidance.

An additional step was necessary for the findings/recommendations obtained from the auditory alerting review. Due to the variety in source type and year published, a rating system was developed. Each source was given a rating based on the type of publication, and the year in which it was published (See Table 1). This rating was one attempt to estimate the credibility and significance of each source, rating higher (e.g., "7A") those sources that were more recent and/or were published in archival publications that require internal/external review and approval.

Table 1: Rating (1-7) based on publication type and Rating (A-D) based on year published

\begin{tabular}{|l|l|l|l|}
\hline Rating & Type of Source & Rating & Years \\
\hline 7 & $\begin{array}{l}\text { Peer Reviewed Journal Articles, } \\
\text { Consensus Standards }\end{array}$ & A & $2000+$ \\
\hline 6 & Government Reports, Books & B & $1980-1999$ \\
\hline 5 & $\begin{array}{l}\text { Conference } \\
\text { Proceedings/Bulletins }\end{array}$ & C & $1960-1979$ \\
\hline 4 & Reports (companies/universities) & D & $<1960$ \\
\hline 3 & Masters/PhD Thesis & & \\
\hline 2 & Journalism & & \\
\hline 1 & Blogs & & \\
\hline
\end{tabular}

Once the relevant and credible findings were identified and organized, the next step in guidance development was to identify convergent themes among the findings/recommendations. During this process, the authors identified findings/recommendations that contradicted one another. The authors attempted to reconcile these contradictions by siding with findings that were most aligned with wellaccepted social theory of human behavior in natural or technological disasters. Also, findings that originated from sources found in archival publications received higher priority, in cases of contradicting guidance. However, there were some contradictory findings in which consensus was not reached, and thus, were not included in this guidance document. 


\subsection{Workshop Development and Outcomes}

Once preliminary guidance was developed, NIST and the Fire Protection Research Foundation conducted a series of workshops. One workshop took place in 2016 and focused on outdoor siren systems, and the second workshop took place in 2017 and focused on short message alerts. The purpose of both workshops was to gather insight/feedback on NIST's interim guidance from expert alerting providers across the U.S.

In 2016, as part of the first-year effort focusing on outdoor siren systems, the Fire Protection Research Foundation hosted a one-day workshop to the use of outdoor siren systems. This workshop brought together researchers from NIST and emergency managers and National Weather Service (NWS) representatives from SW Missouri, Kansas City, Minnesota, South Dakota, and North Texas to understand current siren policies and the processes employed to develop them, especially those policies that exist across multiple jurisdictions. The agenda included presentations on the project's preliminary guidance, discussion about unanswered questions, dialogue on siren policy standardization and its challenges, and discussion of the ways in which NIST guidance could play a role in facilitating the development of siren policies in tornado-prone regions across the U.S. The workshop attendees provided significant feedback on preliminary guidance presented by NIST on the use of outdoor siren systems as a means for public alerting.

In 2017, as part of the second-year effort focusing on short message alerts, the Fire Protection Research Foundation hosted a one-day workshop to the use of short message alerting systems, such as WEA, Twitter, third-party text messaging systems, and others. This workshop brought together researchers from NIST and the University of Kentucky, as well as message providers from local, state, and federal organizations located in regions across the country who were well-versed in the use of short message platforms for emergency alerting purposes. Attendees included emergency managers, public information officers, press secretaries, and government affairs managers from state and local emergency management agencies and universities, as well as warning coordination meteorologists from the National Weather Service, among others. The purpose of this workshop was to present the previously developed preliminary guidance and obtain feedback on its feasibility. Additionally, workshop attendees discussed research gaps in public response to short message alerts, which is provided in more detail in Kuligowski and Doermann (2017).

Based on each alerting research review and workshop feedback from both the 2016 and 2017 workshops, final guidance on public alerting is provided here. The guidance is organized by the framework put forth in the Protective Action Decision Model (PADM), which includes the following stages: pre-decisional processes (receipt, attention, and comprehension), as well as the decisional processes of credibility and assessment of risk, which will be briefly described in the following section.

\section{Guidance on Public Alerting under Imminent Threat}

Evidence-based guidance is provided here on the ways in which to create/disseminate public alerts for those under imminent threat. Guidance on outdoor siren systems is provided first, followed by guidance on short message alerts. Before the guidance is presented, however, the framework under which the guidance is organized, the Protective Action Decision Model, will be briefly described. 
The Protective Action Decision Model (PADM) is selected here as a model to organize guidance on public alerting, using outdoor siren systems and short message alerts. The PADM provides a framework that describes the process of information flow and decision-making that influences protective actions taken in response to natural and technological disasters (Lindell and Perry 2004).

Initially, the individual needs to receive a cue, pay attention to it, and comprehend the meaning associated with the cue (e.g., hearing an alerting signal or seeing a short message alert). These represent the three pre-decisional stages of the PADM, i.e., the stages that determine whether external information is processed such that it can inform the decision-making process (Lindell and Perry 2004). Given that this information is processed, it then needs to be assessed to determine whether the information provided is credible, and in turn, if there is a credible threat. At this stage, the individual decides if there is actually something occurring that may require action. If the individual considers there to be a threat, they next determine whether the threat is relevant to him/her, known as personalizing the threat (or risk). Research has shown that a person's perception of personal risk is highly correlated with taking protective action (Lindell and Perry 2004:51, Mileti and Sorensen 1990, Groner 2009, Perry, Lindell and Greene 1981). The individual tries to gain insight on the potential outcomes of the disaster and what those potential outcomes mean to his or her safety. If the cues are deemed to relate to them, the individual then determines whether it is relevant and pressing. This then requires the individual to determine the nature of the response required at that point in time.

At this stage, the individual engages in a decision-making process to identify a set of possible protective actions from which to choose. After establishing at least one protective action option, an individual engages in protective action assessment of these options and their current action.

If at any stage the individual is uncertain about the situation and if there is perceived time to do so, the individual engages in additional information-seeking actions or they simply wait until additional information is provided to them. If seeking information, they may search for other sources of information (e.g., websites, media, etc.) and/or reach out to other people, e.g., the family unit or work colleagues, to discuss the situation and what to do (also known as the milling process) (Wood et al. 2017; Aguirre, Wegner and Vigo 1998; Turner and Killian 1972; Drabek 1986). The greater the ambiguity involved in the situation, the more likely that individuals will search for additional information that can guide their actions (Mileti and Beck 1975; Mileti and O'Brien 1992). Information seeking is especially likely to occur when individuals think that time is available to gain additional insight. The individual continues in this action until sufficient information is available (or time runs out) (Lindell and Perry 2004). During an incident, information received can be incomplete, ambiguous, or contradictory, causing uncertainty in what is going on and what do to about it (Kuligowski et al. 2014; Sutton, Palen, and Shklovski 2008). In these cases, progress in the stages of the PADM can be significantly delayed and/or promote inefficient or unsafe protective action behavior.

\subsection{Guidance on Outdoor Siren System Alerting for Those Under Imminent Threat}

The PADM will be used to present the guidance on the use of outdoor siren systems for public alerting. The focus of this guidance is to aid alert providers in 1) reaching a wider audience (i.e., increase perception and attention), 2) increasing comprehension (i.e., meaning and understanding), and 3) increasing credibility and the ability of the population to personalize the risk to them and others. As the PADM purports, individuals who follow the decision-making process are more likely to respond safely and effectively.

To reach a wider audience, audible alerts and other information should be provided to all people using push technology (Woody and Ellison 2014; Chandler 2010; Rogers and Sorensen 1991). Push technology 
is technology that disseminates information to the public without requiring them to seek or search for it. Examples of push technology includes outdoor siren systems, as well as public address announcements, NOAA weather radios, and wireless emergency alerts (WEAs). They goal here is to reach as wide an audience as possible, including vulnerable populations (e.g., non-English speakers) (Stokoe 2016; Woody and Ellison 2014; Donner, Rodriguez and Diaz 2012; Bruck and Thomas 2008).

Additionally, it was noted in the literature that vulnerable populations are less vulnerable with a robust social network (Donner, Rodriguez and Diaz 2012; Bruck and Thomas 2008; Laidlaw 2001). Therefore, guidance suggests that alert providers should develop a means of engagement with community leaders in these more vulnerable subpopulations before the next disaster event occurs (Donner, Rodriguez and Diaz 2012). Pre-event engagement allows trust to develop between alert providers and vulnerable populations, and even creates multiple means of alert/warning dissemination to those most vulnerable. For example, in a disaster event, alert providers can reach out to subpopulation community leaders to disseminate disaster information to a wider audience. In addition, guidance suggests the use of alerting technologies that vibrate or flash using a strobe light to promote a wider reach to certain populations (e.g. deaf or blind populations) (Stokoe 2016; Mayhorn 2005; Mogil and Groper 1977).

In order to increase comprehension of the outdoor siren system, alert providers should accompany the siren tone with consistent, specific, and clear information both for people inside and outside the threat area (Woody and Ellison 2014; Kuligowski and Omori 2014; Dobbs and Fung 2009; Rogers 1985). Information can be provided to the public (to accompany outdoor siren systems) via a variety of channels, e.g., public address or announcement systems, radio/televisions, short-message services, Internet, WEAs, and NOAA Weather Radios. Literature sources noted that single alerting systems (e.g., outdoor siren systems alone, and especially ones that provides little or no information) are not adequate (Gregg et al. 2007; Benthorn and Frantzich 1999; Lachman, Tatsuoka and Bonk 1961). When the meaning of the auditory alert is not understood, and even if it is, people will seek confirmation from multiple sources (Rogers 1985). This finding is further complicated with the fact that sirens often are meant to prompt people to seek additional information. Information provided along with any siren tone/signal should be provided by credible, familiar, authoritative sources (including local officials) and the content of the information is also very important (Chandler 2010; Dobbs and Fung 2009).

The content of any accompanying warning message should contain five types of information. These five types are identified as effective in prompting protective action for those under imminent threat (Sutton et al. 2014; Mileti and Peek 2001; Mileti and Sorensen 1990), and include the following:

- Source (i.e., what entity/organization/person is sending this message?),

- Guidance (i.e., what actions should the public take in response to the message?),

- Time (i.e., what hour/day did/will this event occur? Or, by when do people need to act?),

- Location (i.e., which areas are at risk?),

- Hazard/consequence (i.e., what event has/will take place and how dangerous will these events be to the public?).

Additionally, to improve comprehension of the siren alert, as well as increase public trust in the alert, the literature recommends that common standards and practices should be adopted to minimize confusion for the public and to increase trust (Stokoe 2016; Brotzge and Donner 2015). Further, multiple sources recommended to standardize the tone/meaning to reduce confusion (Edworthy 1998). Attempts at standardizing the tone/signal have occurred in other industries; e.g., hospital (Milligan, Allan and Cuthill 2012), buildings (Proulx 2001; Proulx et al. 2001). Additionally, multiple jurisdictions within a region (e.g., Joplin area) and states (e.g., Minnesota) have already begun standardizing siren practices across communities. These could be used as guides to other communities who might be interested in following suite. 
One proposed option is to choose one standard siren tone for all communities (e.g. choose between steady and wail). That way, as people move or travel from community to community, as visitors or tourists for example, they are not faced with different sounding tones for emergency events. Instead, all communities (within a region, state or otherwise) use the same alerting tone for a particular set of hazard events.

Taking this even further, a second proposed option is that the one standard tone could be used by all communities to alert the public of all types of emergencies to which they are exposed. Three justifications for this option can be found in the research. First, research has found that people exposed to multi-tonal systems often cannot remember or distinguish the meanings assigned to multiple tones, and in turn, they are required to seek information (Lindell and Perry 1987). Additionally, in mono-tonal systems, people are always required to seek information because they are never quite sure which current event/hazard to which they are being exposed (Donner, Rodriguez and Diaz 2012). Finally, not all communities are equipped with sirens that have multi-tonal capabilities (Kuligowski et al. 2014). This may be a viable option for communities equipped with outdoor siren systems, only if warning information is provided simultaneously along with the siren alert, and the community members are educated on the changes in siren usage, particularly on the tone and its potentially new meaning.

A method of improving siren alerting comprehension, threat credibility, and personalization of risk is to expand education efforts on these systems, nationwide. Education on the use of these systems should be pushed out to the public so that they cannot avoid hearing, seeing or being exposed to such educational information. Possible examples of ways to educate the public on outdoor siren systems include the following:

- $\quad$ Radio and TV advertisements about outdoor siren alerting disseminated alongside monthly tests (Gregg et al. 2003),

- Developing advertising campaigns on outdoor siren alerts and effective protective actions that depict non-action as undesirable behavior (Farrelly et al. 2002; Proulx et al. 2001),

- A nation-wide “Tornado Day” similar to the nationwide Earthquake 'Shake-out' Drills that occur in the same day each year across the United States (Johnson 2013; Wood and Glik 2012; Green and Petal 2010). These drills would allow people to receive the siren alert, potentially receive accompanying information, and practice taking the recommended protective action. The research shows that practices that have been tested are more likely to be adopted (Arndt and LaDue 2013). Additionally, people talking to each other about their experiences and protective actions taken can encourage others’ participation during the current and future events (Wood and Glik 2012).

Another option for educating the public about outdoor siren systems is to push out educational information to elementary, middle and high school students via disaster education programs and lesson plans (International Federation of Red Cross and Red Crescent Societies 2011; Vitek and Berta 1982). Currently, studies have shown that hazards/disasters activities are under-represented in U.S. classrooms, leaving ample opportunity to include disaster education in school curriculum (International Federation of Red Cross and Red Crescent Societies 2011). As examples, Geography can be used to teach students about human and physical hazards in the locality (Mitchell 2009), homework can be given that promotes student/parent interaction (other disciplines) (Gregg et al. 2003), and/or schools could encourage preparedness among families and school staff (Wood and Glik 2012). Additionally, classes could be offered for adults via Weather Hazard Programs (or stand-alone courses) (International Federation of Red Cross and Red Crescent Societies 2011; Vitek and Berta 1982), applying evidence-based adult education concepts (Arndt and LaDue 2013).

During the outdoor siren system workshop, options were presented to workshop attendees on standardized policies for all-clear alerts and siren testing. These options were developed based on converging policies of communities represented by workshop attendees, since no specific literature or 
research was found on all-clear alerts or siren testing procedures, other than examples found in Ebner (2013). It should be noted that no general consensus was achieved on these two options; favorable and unfavorable opinions were provided on both of the following:

- All-Clear Alerts: All-clear siren signal will not be issued by outdoor siren systems, since people are suspected to be inside taking shelter from the event. There are others way to issue an all-clear alert, e.g., via television, radio, mobile alerting, etc.

- Siren Testing Procedures: Outdoor siren systems will be tested on the same day and time for all communities across the country. These systems will be tested (audibly) one time per month, only. Outdoor siren system testing will not occur during bad weather.

Also during the outdoor siren system workshop, attendees discussed the idea of standardizing policies across the U.S. From this discussion, it was found that a nationwide policy was generally not a favorable option among workshop attendees. More favorable were standardized policies across multiple jurisdictions (perhaps via Integrated Warning Teams) or state-lead efforts.

\subsection{Guidance on Short Message Alerting for Those Under Imminent Threat}

The PADM is also used to present the guidance on the use of short message systems for public alerting. The focus of this guidance is to aid alert providers to 1 ) increase perception and attention paid by the public to the short message alert, 2) increase comprehension of the alert, and 3) increase credibility and the ability of the population to personalize the risk to themselves and others. As the PADM purports, individuals who follow the decision-making process are more likely to respond safely and effectively.

There are certain methods that a short message alert provider can use to widen receipt of the message as well as increase likelihood that people will pay attention to the message. First, alerts should be provided using push technology, i.e., technology that does not require the public to seek out or search for this information, but instead, the information is pushed out to the receiver automatically (Chandler 2010). Additionally, people are more likely to receive information that is disseminated by technology that does not require subscription; i.e., is opt-out in nature (Fischoff and Kadavny 2011; Sullivan, Hakkinen and Piechocinski 2009). Opt-out platforms disseminate information to all people as a default, and require the receiver to opt-out if they wish to no longer receive messages from the system or platform. It should also be noted that people are more likely to follow a system (or refrain from opting out of a system) that remains true to its original purpose or mission (National Research Council 2013). For example, people have been shown to opt-out or un-follow a system that was originally dedicated to emergency messages only, but has more recently been used to disseminate non-emergency messages as well.

Additionally, certain techniques can be used with short message alerts to draw readers' attention to the short message, including disseminating a tone/sound (Kuligowski and Wakeman 2017) or an image/picture simultaneously along with the short message (Vos et al. under review). Other ways of drawing attention to the message text, itself, include the use of ALL CAPS (Sutton et al. 2014), bolded letters and/or different colors for words or phrases to which attention should be drawn (Wood et al. 2015). Short messages that use imperative, directive statements (Sutton et al. 2015b) and/or include a hashtag (\#) (Suh et al. 2010) are also more likely to gain attention (Sutton and Kuligowski under review).

Guidance is also provided on the ways to increase message comprehension. The first step is ensuring that the short message contains the appropriate content. The five categories of important short message content include the source of the message, the type of hazard and its consequences, the location of the 
hazard, the timeline of the hazard, and the actions that should be taken by the message recipient (Sutton et al. 2014; Mileti and Peek 2001; Mileti and Sorensen 1990).

Once the message contains all important information, message providers should ensure that the message's language is clear. The following can be done to improve message clarity and in turn, message comprehension:

- $\quad$ Reduce and if possible, remove, abbreviations and jargon. Clearly spell out all words, including the source of the message and timing (i.e., time zones) (Cao, Boruff and McNeill 2016; Bean et al. 2016; Bennett 2015; Temnikova, Vieweg and Castillo 2015; Department of Justice 2012).

- Eliminate spelling errors (Sutton and Woods 2016; Woody and Ellison 2014).

- When identifying hazard and/or safe zones, use terminology that is familiar to the receivers.

o Familiar terminology can include the use of a local community and/or city instead of county names, which may not be as familiar. (Bean et al. 2016).

o Additionally, familiar terminology can include well-known (local) landmarks (e.g., national parks, road names [not mile markers], and suburbs) (Cao, Boruff and McNeill 2016; Kuligowski et al. 2013; Hui et al. 2012).

The message providers may need to pilot test messages for particular audiences, and this can be done using language and readability testing (Kuligowski and Omori 2014).

Guidance is also provided on message comprehension specifically for Twitter alerts. Since research has shown that certain conventions can inhibit message clarity (Temnikova, Vieweg and Castillo 2015), guidance is provided here to avoid user-mentions in alert messages targeted to those under imminent threat. Additionally, message providers should place hashtags at the end of the message, only, and limit use of hashtags to two or less (per alert message).

Guidance can also be provided on ways to improve short message alerts such that the message prompts receivers to perceive the threat as credible and to personalize the risk. One way is to provide appropriate information about the message source (Mileti and Sorensen 1990). The source of the message should be clearly stated, spelled out in full (i.e., without abbreviations or acronyms) (Bean et al. 2016), and perceived as credible by the receiving population (Wood et al. 2015; Liu, Fraustino and Jin 2015). Additionally, the source of the message should be listed first (Bean et al. 2016). Research shows that the appropriate order of message characteristics for 280 c messages is as follows: Source, hazard, location, timeline and guidance (Wood et al. 2015). The appropriate order of message characteristics for $90 \mathrm{c}$ messages is as follows: Source, guidance, hazard, location, and time.

The message style is also important, especially in prompting public response (Wood et al. 2015; Cao, Boruff and McNeill 2016). Certain words or phrases can be used to communicate the following:

- The seriousness of the event (e.g., "imminent danger”, “immediate evacuation”, "urgent”, or “critical”),

- The consequences of the risk if the receiver does not act (Sutton and Woods 2016)

- The actions that should be taken in response to the event (e.g., "Take action now!" or "Evacuate immediately").

Additionally, imperative or instructional style voice can better communicate the message, especially when relaying the protective action(s) that should be taken (Sutton et al. 2015a).

Finally, message receivers would benefit from the receipt of additional information, above and beyond the information received via short message alerts. There are multiple ways available to provide additional information via short message alerting platforms. These methods include providing a link (or URL) to other websites within the short message, linking to or associating the message with maps or other 
graphics ${ }^{2}$, and/or extending the length of the short message to hold a larger number of characters (e.g., WEAs allowing for 360c in the future). An additional method available is known as "threading the message” (Sutton et al. under review). Threading the message involves providing short message recipients with a sequence of short messages (in series), all at one time, about a particular event. Threaded messages should be numbered to identify the order in which the messages are disseminated (and should be received).

If options are available to send additional information, the public would benefit from message providers expanding upon various components of a short message alert, including message source, hazard information, location specifics, event timing and/or guidance on protective actions to be taken by the public. The following list provides examples on ways to expand on each of these:

- The source of the message could be expanded upon by spelling out the entire name and even the individuals responsible for crafting the message,

- Additional information could be provided on the hazard by adding details about the hazard's impacts and consequences of the hazard (Sutton and Woods 2016; Wood et al. 2015),

- Additional details on hazard location can include information on where the receiver is in relation to the event, a task at which maps can be particularly helpful (Bean et al. 2016; Wood et al. 2015)

- The timing (or a timeline) of the event can be expanded upon by spelling out abbreviations that are currently used to express timing and time zones

- For guidance, additional information can expand upon current methods; e.g., "shelter in place” or simply "to shelter", by instructing individuals using imperative or instructional message style exactly how and where to take shelter (Sutton et al. 2015a). Similarly, instead of instructing individuals to evacuate (only), additional information could be provided to recipients on evacuation routes and/or methods for evacuation (Wood et al. 2015).

Work is currently in review providing example short message templates for 90-c and 360-c WEAs as well as 280-c Twitter alerts to be disseminated for those under imminent threat (Sutton and Kuligowski under review).

\section{Unanswered Questions}

As part of both the outdoor siren system and the short message alerting literature reviews, several unanswered questions arose. These questions are listed below, as bullets, to provide examples of future research needs and potential future guidance.

- How frequently should alert originators send/initiate alerts? Related to short message alerts, how can an alert originator make it clear that the message (most recently disseminated) is the most upto-date?

- How do alert originators best reach at-risk or vulnerable populations?

- What are the best mechanisms for alert originators to test the effectiveness of their messages, or siren tones?

- How can a community provide closure after an event? Should alert originators issue a final communication (“all clear" or "remain alert” notice); Note: An all-clear may be more useful for some types of disasters than others (Woody and Ellison 2014).

- What should/can be done as far as public educational campaigns for public alerting?

- Whom (what sources - both individual or organizational) do populations most trust?

\footnotetext{
${ }^{2}$ There are requirements that graphics disseminated via short message technology or posted to the web be 508 compliant (Please see: General Services Administration, Government-wide Section 508 Accessibility Program, https://www.section508.gov/).
} 
- Does the alert originator have the capability to monitor responses (e.g., feedback after the alert is disseminated)?

- Related to outdoor siren systems, what is an appropriate time period for sounding the tone (for both the emergency alert and the testing period)?

\section{Summary}

This report presents evidence-based guidance for communities on the creation and provision of public alerts, specifically outdoor siren systems and short message alerts. These potential improvements to both outdoor siren system and short message alerts would allow the alerts to reach a wider audience (i.e., increase perception and attention), increase comprehension, invoke credibility, evoke urgency, and in turn, increase likelihood of safe and effective public response. As with any document, there are gaps in the research that hinder the ability to provide guidance on certain topics, including alerting frequency, reaching at-risk populations, testing of alerting effectiveness, alerting/warning closure, alerting education, source credibility, and alert monitoring. Additional questions focused specifically on outdoor siren systems include appropriate time periods for alerting as well as testing the system (in non-emergency periods). In the future, as research gaps are addressed, additional editions of this document would be useful to enhance the findings and analysis provided here. 


\section{References}

Aguirre, B. E., Wenger, D., and Vigo, G. (1998). "A Test of the Emergent Norm Theory of Collective Behavior.” Sociological Forum 13(2): 301-320.

Arndt, D. S., and LaDue, D. S. (2013). Applying Concepts of Adult Education to Improve Weather and Climate Literacy. Physical Geography, 29(6), 487-499.

Bean, H., Liu, B. F., Madden, S., Sutton, J., Wood, M. M., and Mileti, D. S. (2016). Disaster warnings in your pocket: How audiences interpret mobile alerts for an unfamiliar hazard. Journal of Contingencies and Crisis Management, 24(3), 136-147.

Bennett, D. M. (2015). Gaps in Wireless Emergency Alert (WEA) Effectiveness. Public Administration Faculty Publications. 82. Accessed August 8, 2017

http://digitalcommons.unomaha.edu/pubadfacpub/82/?utm_source=digitalcommons.unomaha.edu\%2Fpu badfacpub\%2F82\&utm medium=PDF\&utm campaign=PDFCoverPages.

Benthorn L, Frantzich H. (1999). Fire Alarm in a Public Building: How do people evaluate information and choose an evacuation exit? Fire and Materials 23(6), 311-315.

Brotzge, J., and Donner, W. (2015). General Policy for Activating Outdoor Warning Siren Systems for Severe Weather: Survey of Emergency Managers. Natural Hazards Review, 16(2).

Bruck D, Thomas I. (2008). Comparison of the Effectiveness of Different Fire Notification Signals in Sleeping Older Adults. Fire Technology, 44(1), 15-38.

Cao, Y., Boruff, B. J., and McNeill, I. M. (2016). Is a picture worth a thousand words? Evaluating the effectiveness of maps for delivering wildfire warning information. International Journal of Disaster Risk Reduction, 19, 179-196.

Chandler R. C. (2010). Emergency Notification. Santa Barbara, CA: Praeger.

Department of Justice. (2012). AMBER Alert Best Practices.

Dobbs M, Fung A. (2009). Enhancing Occupant Response through Neuro Linguistics (Poster Paper). Umow Lai Pty. Ltd., Victoria, Australia.

http://www.umowlai.com.au/pdf/publications/Fire/Enhancing\%20Occupant\%20Response\%20Through\% 20Neuro\%20Linguistics.pdf

Donner, W. R., Rodriguez, H., and Diaz, W. (2012). Tornado Warnings in Three Southern States: A qualitative analysis of public response patterns. Journal of Homeland Security and Emergency Management, 9(2).

Drabek, T. E. (1986). Human System Responses to Disaster: An Inventory of Sociological Findings. New York, NY: Springer-Verlag.

Ebner, N. W. (2013, December). A Study of Emergency Management Policy Regarding the Use of Tornado Sirens During Severe Weather in the State of Missouri . Proposed Masters Thesis. Columbia, Ohio, United States. 
Edworthy J. (1998). What makes a good alarm? IEE Colloquium Digest on 'Medical Equipment Alarms: The Need, the Standards, the Evidence' (pp. 5-8). Ref. No 1998/432, The Institution of Electrical Engineers.

Farrelly, M. C., Healton, C. G., Davis, K. C., Messeri, P., Hersey, J. C., and Haviland, M. L. (2002). Getting to the Truth: Evaluating National Tobacco Countermarketing Campaigns. American Journal of Public Health, 92(6), 901-907.

FCC News. (2016). "FCC Strengthens Wireless Emergency Alerts as a Public Safety Tool.” News release. September 29, 2016. Accessed August 18, 2017.

http://transition.fcc.gov/Daily_Releases/Daily_Business/2016/db0929/DOC-341504A1.pdf.

Federal Communications Commission. (2016). FCC 16-127 Report and Order and Further Notice of Proposed Rulemaking, September 26, 2016. Accessed September 30, 2017

https://apps.fcc.gov/edocs_public/attachmatch/FCC-16-127A1.pdf.

Fischhoff, B. and Kadvany, J. (2011). Risk: A very short introduction. Oxford University Press.

Green, R., and Petal, M. (2010). Lessons Learned from School Participation in the 2008 Shakeout. Bellingham: Western Washington University.

Gregg, C. E., Houghton, B. F., Paton, D., Johnston, D. M., Swanson, D. A., and Yanagi, B. S. (2007). Tsunami Warnings: Understanding in Hawai'i. Natural Hazards, 40(1), 71-87.

Gregg, C. E., Houghton, B. F., Paton, D., Swanson, D. A., and Johnston, D. M. (2003). Community Preparedness for Lava Flows from Mauna Loa and Hualalai Volcanoes, Kona, Hawai'i. Bulletin of Volcanology, 66(6), 531-540.

Groner, N. (2009). “A Situation Awareness Analysis for the Use of Elevators During Fire Emergencies.” Pp. 61-72 in 4th International Symposium on Human Behavior in Fire: Conference Proceedings. London, UK: Interscience Communications.

Hui, C., Tyshchuk, Y., Wallace, W. A., Magdon-Ismail, M., and Goldberg, M. (2012, April). Information cascades in social media in response to a crisis: a preliminary model and a case study. In Proceedings of the 21st International Conference on World Wide Web (pp. 653-656).

International Federation of Red Cross and Red Crescent Societies. (2011). Public Awareness and Public Education for Disaster Risk Reduction: A Guide. Guidance Document. Geneva, Switzerland: International Federation of Red Cross and Red Crescent Societies.

Johnson, V. A. (2013). An Impact Evaluation of ShakeOut, an Earthquake and Tsunami Drill in Two Coastal Washington State School Districts. Wellington: GNS Science Report.

Kuligowski, E. D., Lombardo, F. L., Phan, L. T., Levitan, M. L., and Jorgensen, D. P. (2014). Final Report, National Institute of Standards and Technology (NIST) Technical Investigation of the May 22, 2011, Tornado in Joplin, Missouri, NIST NCSTAR 3, National Institute of Standards and Technology: Gaithersburg, MD.

Kuligowski, E. D., Phan, L. T., Levitan, M. L., and Jorgensen, D. P. (2013). Preliminary Reconnaissance of the May 20, 2013, Newcastle-Moore Tornado in Oklahoma, NIST Special Publication 1164, National Institute of Standards and Technology: Gaithersburg, MD. 
Kuligowski, E.D. and Omori, H. (2014). General Guidance on Emergency Communication Strategies for Buildings, 2nd Edition. NIST Technical Note 1827, National Institute of Standards and Technology:

Gaithersburg, MD.

Kuligowski, E.D. and Doermann, J. (2018). A Review of Public Response to Short Message Alerts under Imminent Threat. NIST Technical Note 1982, National Institute of Standards and Technology:

Gaithersburg, MD.

Kuligowski, E.D. and Wakeman, K. (2017). Outdoor Siren Systems: A review of technology, usage, and public response during emergencies. NIST Technical Note 1950, National Institute of Standards and Technology: Gaithersburg, MD.

Lachman, R., Tatsuoka, M., and Bonk, W. J. (1961). Human Behavior during the Tsunami of May 1960. Science, 133(3462), 1405-1409.

Laidlaw, E. (2001). The Controversy over Outdoor Warning Sirens. Weatherwise, 63(1), 16-25.

Lindell, M. K. and Perry, R. W. (2004). Communicating Environmental Risk in Multiethnic Communities. Sage Publications. Thousand Oaks, CA.

Lindell, M. K., and Perry, R. W. (1987). Warning Mechanisms in Emergency Response Systems. International Journal of Mass Emergencies and Disasters, 5(2), 137-153.

Liu, B. F., Fraustino, J. D., and Jin, Y. (2015). How disaster information form, source, type, and prior disaster exposure affect public outcomes: Jumping on the social media bandwagon? Journal of Applied Communication Research, 43(1), 44-65.

Mayhorn CB. (2005, November). Cognitive Aging and the Processing of Hazard Information and Disaster Warnings. Natural Hazards Review, 6(4), 165-170.

Mileti, D. S. and Beck, E. M. (1975). "Communication in Crisis: Explaining evacuation symbolically.” Communication Research 2(1): 24-49.

Mileti, D. S. and O’Brien, P. W. (1992). “Warnings during Disasters: Normalizing communicated risk.” Social Problems 39(1): 40-57.

Mileti, D. S. and Peek, L. (2001). “Hazards and Sustainable Development in the United States.” Risk Management: An International Journal 3(1): 61-70.

Mileti, D. S. and Sorensen, J. H. (1990). Communication of Emergency Public Warnings. ORNL-6609, Oak Ridge: National Laboratory.

Milligan, P., Allan, J., and Cuthill, J. (2012). 'Name That Tune': Alarms in Critical Care- How Good are We at Recognizing Them? Journal of the Intensive Care Society, 13(2).

Mills, A., Chen, R., Lee, J., and Raghav Rao, H. (2009). Web 2.0 emergency applications: How useful can Twitter be for emergency response? Journal of Information Privacy and Security, 5(3), 3-26.

Mitchell , J. T. (2009). Hazards Education and Academic Standards in the Southeast United States. International Research in Geographical and Environmental Education, 18(2), 134-148. 
Mogil, H. M., and Groper, H. S. (1977). NWS's Severe Local Storm Warning and Disaster Preparedness Programs. Bulletin of the American Meteorological Society, 58(4), 318-324.

National Research Council. (2013). Public response to alerts and warnings using social media: report of a workshop on current knowledge and research gaps. National Academies Press.

National Oceanic and Atmospheric Administration (NOAA). (2014). NWS weather fatality, injury and damage statistics. Found online at http://www.nws.noaa.gov/om/hazstats.shtml. Accessed 10 May 2015.

National Oceanic and Atmospheric Administration (NOAA). (2011). NWS Central Region Service Assessment Joplin, Missouri, Tornado - May 22, 2011. National Weather Service, Central Region Headquarters, Kansas City, MO.

Perry, R. W., Lindell, M. K., and Greene, M. R. (1981). Evacuation Planning in Emergency Management. Lexington, MA: Lexington Books.

Proulx G. (2001, May). Occupant Behaviour and Evacuation. Proceedings of the $9^{\text {th }}$ International Fire Protection Symposium, Munich, Germany, 219-232.

Proulx, G., Laroche, C., Jaspers-Fayer, F., and Lavallee, R. (2001). Fire Alarm Signal Recognition. National Research Council Canada.

Rogers G. O. (1985, September). Human Components of Emergency Warning: Implications for planning and management (Planning Report, FEMA Cooperative Agreement EMW-K-1024 with University of Pittsburgh). Washington, DC: Federal Emergency Management Agency.

Rogers, G. O., and Sorensen, J. H. (1991). Diffusion of Emergency Warning: Comparing empirical and simulation results. Risk Analysis, 117-134.

Stokoe, M. R. (2016). Putting People at the Centre of Tornado Warnings: How perception analysis can cut fatalities. International Journal of Disaster Risk Reduction, 17, 137-153.

Suh, B., Hong, L., Pirolli, P., and Chi, E. H. (2010, August). Want to be retweeted? large scale analytics on factors impacting retweet in twitter network. In Social computing (socialcom), 2010 IEEE Second International Conference (pp. 177-184).

Sullivan, H. T., Häkkinen, M. T., and Piechocinski, D. (2009). Improving participation, accessibility and compliance for campus-wide mobile emergency alerting systems. In International Workshop on Mobile Information Technology for Emergency Response (pp. 32-40). Springer, Berlin, Heidelberg.

Sutton, J. N., and Kuligowski, E. D. (under review). Alerts and Warnings on Short Messaging Channels: Guidance from an expert panel process. Natural Hazards Review.

Sutton, J., Vos S. C., Wood, M., and Turner, M. (second review). Designing effective tsunami messages: The role of short messages and fear in warning response. Weather, Climate and Society.

Sutton, J., and Woods, C. (2016). Tsunami Warning Message Interpretation and Sense Making: Focus Group Insights. Weather, Climate, and Society, 8(4), 389-398.

Sutton, J., League, C., Sellnow, T. L., and Sellnow, D. D. (2015a). Terse messaging and public health in the midst of natural disasters: The case of the Boulder floods. Health communication, 30(2), 135-143. 
Sutton, J., Gibson, C. B., Spiro, E. S., League, C., Fitzhugh, S. M., and Butts, C. T. (2015b). What it takes to get passed on: message content, style, and structure as predictors of retransmission in the Boston Marathon bombing response. PLoS one, 10(8), e0134452.

Sutton, J., Spiro, E. S., Johnson, B., Fitzhugh, S., Gibson, B., and Butts, C. T. (2014). Warning tweets: Serial transmission of messages during the warning phase of a disaster event. Information, Communication \& Society, 17(6), 765-787.

Sutton, J., Palen, L., and Shklovski, I. (2008). Backchannels on the front lines: Emergent use of social media in the 2007 Southern California fire. proceedings of Information Systems for Crisis Response and Management Conference (ISCRAM), Washington DC. Washington DC.

Temnikova, I., Vieweg, S., and Castillo, C. (2015, May). The case for readability of crisis communications in social media. In Proceedings of the 24th International Conference on World Wide Web (pp. 1245-1250).

Turner, R. H. and L. M. Killian. (1972). Collective Behavior. Englewood Cliffs, NJ: Prentice Hall, Inc.

Vitek, J. D., and Berta, S. M. (1982). Improving Perception of and Response to Natural Hazards: The need for local education. Journal of Geography, 81(6), 225-228.

Vos, S.C., Sutton, J., Gibson, C. B., and Butts, C. (second review). Theorizing the diffusion of public health messages on social networking sites. Journal of Health Communication.

Wood, M., Mileti, D.S., Bean, H., Liu, B.F., Sutton, J., and Madden, S. (2017). Milling and Public Warnings. Environment and Behavior (published online).

Wood, M., Bean, H., Liu, B., and Boyd, M. (2015). Comprehensive testing of imminent threat public messages for mobile devices: Updated Findings. College Park: National Consortium for the Study of Terrorism and Responses to Terrorism.

Wood, M. M., and Glik, D. (2012). Engaging Californians in a Shared Vision for Resiliency: Practical lessons learned from the Great California Shakeout. Sacramento: State of California Seismic Safety Commision.

Woody, C., and Ellison, R. (2014). Maximizing trust in the wireless emergency alerts (WEA) service. Software Engineering Institute. 